\title{
Other Method, Specify Below
}

National Cancer Institute

\section{Source}

National Cancer Institute. Other Method, Specify Below. NCI Thesaurus. Code C158759.

A directive to specify the method below which is other than is listed on the form. 